\title{
Expanding Our Community: Independent and Interdependent Factors Impacting Refugees' Successful Community Resettlement
}

\author{
DeBrenna LaFa Agbényiga \\ Salamatu Barrie \\ Valentina Djelaj \\ Stephanie J. Nawyn
}

\begin{abstract}
Evidence suggests that despite the aid from resettlement agencies, many refugees find the resettlement process extraordinarily stressful and have reported significant negative mental and physical health outcomes. The literature on refugee resettlement often focuses on the challenges that these individuals encounter in their new environment. However, less research has focused on community barriers and lack of support issues that can prevent refugees from resettling in the U.S. Using qualitative data collected from Burmese and Burundian refugee groups, this article examines the impact of social structures on the resettlement process. Results indicate that gaps in service delivery such as employment and housing are affected by support from the resettlement agencies and the refugees' social support network. Results of this study contribute to the knowledge based on how best to assist refugee families.
\end{abstract}

Keywords: Refugee resettlement, refugee families, service provision, community, and socialization

\section{INTRODUCTION}

According to the latest United Nations High Commission for Refugees [UNHCR], (2010) statistics, there are 43.3 million forcibly displaced people worldwide. Of the millions who are displaced, 15.2 million people are classified as refugees. The UNHCR (1951) defines refugees as:

anyone who, owing to a well-founded fear of being persecuted for reasons of their race, religion, nationality, membership in a particular social group or political opinion outside of their country of nationality, and is unable to, or owing to such fear, is unwilling to avail themselves of the protection of their country (Article 1A[2]).

Unlike other immigrants who have a choice about their future environments, many refugees have little knowledge of the location or the culture of their new host nations. Most have been forced from their home countries, living in transitional housing, and are uncertain about their future before they resettle in a new country (Singer \& Wilson, 2006). While residing in refugee camps, many are tortured, starved and beaten, exposed to a variety of infectious diseases, raped, and/or experience harassment before coming to their new environment (Costa, 2006; Weinstein, Sarnoff, Gladstone, \& Lipson 2000). When refugees arrive to their resettled communities, they often have significant physical

DeBrenna LaFa Agbényiga, Ph.D., LMSW, is an Assistant Professor in the School of Social Work, Stephanie J. Nawyn, Ph.D., is an Assistant Professor in the Department of Sociology, and Salamatu Barrie is a Graduate Student in the Department of Sociology, all at Michigan State University. Valentina Djelaj is a Graduate Student at Wayne State University in Detroit, MI.

Copyright $(2012$ Advances in Social Work Vol. 13 No. 2 (Summer 2012), 306-324 
and mental health needs that must be acknowledged during the resettlement process. Furthermore, they must also deal with the loss of extended family and kinship networks, which are imperative to successful resettlement.

\section{Resettlement Process in the U.S}

Resettlement in the U.S. is an arduous process that can cause significant strain on the individual. According to the latest Department of State statistics, the United States is the largest host nation for resettled refugees with an estimate of 3 million individuals in 2010 (U.S. Department of State, 2010). As part of an agreement between the government and refugee agencies, upon arrival, refugees are met at the airport in the United States by resettlement agency personnel. At this point, refugees are provided with furnished apartments, appliances, climate-appropriate clothing and some foods typical of the refugee's culture. Shortly after arrival at their new environment, the agencies are required to assist the refugees with applying for a Social Security card, registering children for school, enrolling adults in English as a Second Language (ESL) courses, arrange medical and psychiatric appointments (if applicable), and connect them with needed social or language services. The resettlement agencies also collaborate with the Department of Health and Human Services' Office of Refugee Resettlement to connect families with long-term cash, medical, and food assistance programs that provide support to refugees for six months (U.S. Department of State, 2010).

Given the trauma that refugees are exposed to before their arrival in the U.S., it is imperative that they receive the appropriate resources and services from resettlement agencies. For families from non-western countries, issues such as new language acquisition, employment training, medical attention, education and access to community resources are a high priority (Deacon \& Sullivan, 2009; Lewig, Arney, \& Salveron 2010; Nawyn, Gjokaj, Agbényiga, \& Grace, 2012; Willis \& Nkwocha, 2004).

This article assessed the services that refugee families received from several resettlement agencies in a Mid-Western state during the resettlement period. Primarily, we focused on the impact of support structures on the community of two different ethnic groups, Burmese and Burundians, and propose solutions that can increase refugees' wellbeing and quality of life in their new community settings. Furthermore, we delved into discussions of how support from agencies and social networks assist refugees to ensure their well-being.

\section{Refugee Support Structures}

Research suggests that interactions with family members, peers, friends, and professionals play an essential role during transitional periods (Simich, Beirser, Stewart, \& Mwakarimba, 2005). More specifically, support from social networks can improve individuals' wellbeing, provide assistance, and bring comfort during times of uncertainty (Bosch \& Bergen, 2006; Carlson, McNutt, Choi, \& Rose, 2002; Oetzel, Duran, Jiang \& Lucero, 2007). These studies demonstrate that perceptions of support and/or actual supportive networks can mitigate harmful outcomes such as substance abuse, alcohol use, and mental health issues. The absence of social support have been linked to heightened 
levels of stress, anxiety, depression, suicide, as well as an increase in physical health problems (Goodkind, Gillum, Bybee, \& Sullivan, 2003; Oetzel et al., 2007). Studies on immigrant populations indicate that during resettlement, informal sources of support such as friends and family reduce stress, improve well-being, increase access to employment, education, and other basic needs, and foster a strong sense of belonging amongst members of similar ethnic background (Simich et al., 2005). In the context of refugees, very few studies exist that focus specifically on the importance of social networks and other support structures in refugee development. However, Schweitzer and colleagues (2006) found that the presence of kinship networks and social support were better determinants of Sudanese refugees' mental health than the utilization of support from a wider community. They also found that refugee kinship ties with their extended family were important sources of both emotional and instrumental support (Schweitzer, Melville, Steel, \& Lacherez, 2003).

Similar results were reported by Simich and colleagues (2003) who found that informational, instrumental, and emotional support are ranked as high priority during resettlement. Both these studies suggest that refugees were comfortable seeking aid from a member of their community than from resettlement agencies and other community organizations. Furthermore, this study also suggested that the lack of meaningful supportive relationships from both formal sources, such as resettlement and community agencies, and informal sources, such as friends and family, decreases refugees' wellbeing. For example, participants who were isolated from relatives and peers in their new environment often experienced depression symptomatology, often taking medication to cope with the challenges of resettlement. Results also indicated that refugees who were able to find individuals and agency staff who empathized and shared their experiences were better able to cope with the stress that occurs during resettlement (Simich, Beiser, \& Mawani, 2003).

Another study by Simich and colleagues (2005) highlighted the importance that service providers and policy makers who work with refugees place on the importance of good supportive networks during the resettlement process. Results from focus groups with service providers and policy makers demonstrated that refugees with social support are better able to share their experiences and problems, reduce stress, and feel empowered. They are also more effective at building community supports to assist other newcomers from similar ethnic backgrounds facing comparable circumstances. Service providers and policy makers also recognized the importance that different types of support have on refugees' successful resettlement. For example, information support was seen as critical because refugees are better able to share and disseminate information about resources in the community. Emotional support decreased isolation and loss of kinship ties, helping build connections with others in their new environment, particularly with those who may have also experienced similar issues. Affirmation from other peers and family members allowed refugees to become empowered to meet new challenges.

The results from the aforementioned studies illustrate the importance of supportive structures to assist refugees' in their well-being and adjustment to new communities. Given there is limited knowledge about newly resettled refugees from different ethnic 
groups in the United States, this study adds to the research knowledge on experiences of refugees from diverse ethnic groups.

\section{Resettlement History of Burmese and Burundians}

Burmese and Burundians were chosen for this study for three reasons. First, they represented the two largest newly resettled refugee groups currently residing in neighboring mid-west cities. Research indicates that cultural barriers make it difficult to recruit study participants from refugee populations. Thus, recruiting from populations that are highly represented in the area increases the likelihood of having a representative study sample. Second, there is limited knowledge of the Burmese and Burundian's adaptation patterns. Finally, the emphasis on Burmese and Burundian refugees was due to the differences in migration histories between and within both groups. Differences such as ethnicity, education level, and socio economic status (SES) are believed to be contributing factors that lead to different adaptation patterns in the resettlement process. The culmination of these three factors led to a larger study which investigated various resettlement factors from an individual, family, and group perspective as a means to understand and provide recommendations for agencies who work with these newly resettled populations.

Historically, refugee resettlement in the United States was typically linked to European and Central Asian countries. Current estimates indicate that the U.S. has resettled over 900,000 refugees from former Soviet Union countries, and neighboring nations (U.S. Department of State, 2010). However, given the political turmoil, economic instability, and religious persecutions that have impacted East Asian and African countries, reports indicate that there are new waves of refugee populations that are entering the U.S. (Adepoju, 2006; Docquier, Lohest, \& Marfouk, 2007). In particular, over 1.3 million refugees from Vietnam, Laos, Cambodia, and Burma (currently known as Myanmar), and other neighboring Asian countries are currently residing in the U.S. with recent reports estimating that the U.S. will grant an additional 18,500 ethnic minority Burmese asylum in 2011 (U.S. Department of State, 2010).

Burmese refugees were displaced from what is now called Myanmar. Under orders from the Burmese government, the military perpetrated gross human rights violations such as forced labor, arbitrary execution, destruction of food crops and forced relocation of villages that belonged to ethnic minority groups such as the Karen and Chin (Lang 2002; Wright, 2008). Many of the refugees fled to camps in Thailand or Malaysia where they lived as unauthorized immigrants until the United Nations made them eligible for resettlement processes. While residing in refugee camps, the Burmese faced discrimination, forced labor and relocation, poor wages, killing of family members and a lack of basic human rights protection from the Thai or Malaysian governments (Draminsky-Petersen, Worm, Zander- Olsen, Ussing, \& Harding, 2000). Another study found that many Burmese refugees in Thai camps reported experiencing high levels of depression, anxiety and post-traumatic stress disorder (Cardoz, Talley, Burton, \& Crawford, 2004).

Refugees from Africa who have resettled in the U.S. have primarily been from Somalia (nearly 95,000) or Ethiopia (over 45,000) as reported by recent statistical data 
(U.S. Department of State, 2011). Since gaining its independence from Belgium in 1962, Burundi has been rifted with ethnic tensions, civil wars and coups d'état. Ethnic tension, class warfare, and military coups between the Bahutu and Batutsi have led to destruction, death, and displacement. As is typical in most conflict situations, hundreds of thousands of people were killed; rape was used as a strategic weapon, and numerous violations of human rights were committed (Hoofnagle \& Rothe, 2010). Those who were not killed fled to neighboring Rwanda, Tanzania, and the Democratic Republic of Congo (Daley, 1991). It is estimated that more than 150,000 refugees fled from Burundi in 1972 and another 400,000 in 1993 (Haver, Hatungimana, \& Tennant, 2009). Similar to the Burmese refugees, Burundians from Rwanda and Tanzania encountered several challenges such as lack of food, little security, exposure to high stress, and constant harassment from government officials during their time in camps (International Crisis Group [ICG], 1999; Verwimp \& Van Bavel, 2005). For example, Whitaker (2002) found that many refugees living in Western Tanzania experienced a shortage of food, water and proper health care facilities. In fact, rising food prices for staples such as sugar, salt, and grain had resulted in further financial instability. Many refugees were forced to work as cheap laborers for Tanzanian farmers often taking food as payments rather than money. Furthermore, Whitaker (2002) found that the camps were associated with drunkenness, sexual promiscuity, increased incidence rates of HIV and STIs, and illegal activities.

While the literature on refugee resettlement is sparse, particularly with respect to specific groups' adaptation processes, studies have highlighted the importance of support from peers and formal institutions in refugees' successful resettlement. This pilot study examined the impact of newly formed interpersonal relationships on resource acquirement. Our aims were to: (a) examine the impact of formal and resource support on refugee well-being; (b) study the extent to which informal support impacts successful resettlement and; (c) compare ethnic difference in support structures. Given that both groups, Burmese and Burundians, have experienced years, in some cases, decades of instability, research must look beyond individual level challenges and focus on the impact of agency support and social networks on resettlement from a group perspective.

\section{METHOD}

The data analyzed for this paper was part of a larger qualitative study that examined the adaptation and resettlement experiences of refugees from Burma and Burundi. From the overall sample $(n=36)$, seventeen were female and nineteen were male. The mean age at the time of the interviews was 39 years old with a range between 19 and 58 years old. From the total sample, thirteen participants (5 women and 8 men) were Burmese. All Burmese women were married and three of the men were single. Of the married couples, four had at least one child $(\mu=1.75)$ and none of the single males had children. All of the Burmese participants with children resided with all of their children in the same household. The mean age for the Burmese was 29.8 with a range between 19 years old and 38 years old. Most of the participants in the sample had been displaced from Myanmar for less than three years and were either ethnic Karen or Chin. All of the Burmese had at least a primary school education with an average of eight to nine years of 
formal schooling. Many of them had professional jobs or were students prior to fleeing Burma or Thailand. All of our participants spoke the Chin dialect or Burmese.

Twenty-three adult Burundians (12 women and 11 men) were recruited for this study. Of the total number of Burundian participants, nine were couples with children, two were single parent families, one male had no children, and two did not mention children in their interviews. Most had been farmers or small trades people with little or no formal education, and many were young (under 21 years of age) when they fled Burundi. The mean age was 45.2 years old at the time of the interviews with a range between 33 and 58 years old. Many of the families (95\%) in the sample still had family members back in Burundi or had children from other relationships (adults and small children) that were not currently residing with them. Often, these parents were and continued to be financially supporting families (i.e. parents, siblings, and other children) in Burundi, Tanzania, or Rwanda. Overall, our participants from Burundi had spent 30-35 years in exile before being resettled in the United States. All of the Burundian participants spoke Kirundi and very little English. Since the focus of the study was to examine refugee resettlement, all participants (both Burmese and Burundians) had to have been in the U.S. for more than 120 and less than 180 days. This is because after six months, refugees are viewed as being independent and not in need of or eligible for guided services through the refugee resettlement agencies.

\section{Recruitment and Selection}

Potential participants were recruited through two Mid-Western State resettlement agencies. The Principal Investigators (PIs) of the study worked with agency staff to recruit Burmese and Burundian refugees. To be eligible, participants had to be 18 years or older and had been resettled in the area within the last 180 days. A list of potential participants was compiled by agency staff and sent to the PIs. All identifying information was replaced with case numbers (not connected to their agency specified case number), so the investigators only saw demographic information such as country of origin, gender, and the number of people in their household. The PIs targeted matched pairs (husband and wife) as potential participants for their study. This criterion was included in the sampling frame because the investigators were interested in examining the gender differences related to the resettlement process. By examining the experiences of couples, the PIs hoped to capture the dynamics of family relationships.

Once a potential participant was selected, the agency staff contacted the individual and provided detailed information about the study. The prospective participant was told that the purpose of the study was to examine the services they received and to learn more about the support given within and outside the agency during their resettlement period. They were then asked if they would like to be part of the study, knowing that their participation was voluntary with no penalty if they chose not to take part. In addition to the description of the study, potential participants were also told of the benefits which included a \$40 gift card as compensation and the opportunity to have their experiences heard. If the individual wanted to participate in the study, the agency staff asked their permission to share their contact information with the PIs. This recruitment protocol was necessary because of the agency's IRB requirement. Confidential information such as 
names and contact information could not be given without the permission of the individuals. In an effort to protect the rights of the participants, the PIs were required to obtain IRB approval from the agencies and the university. During the recruitment process, the PIs worked with one person of contact at each agency. This was done to build and facilitate trust between the researchers, participants, and agencies. By using one person to contact participants, the PIs hoped to ease the fears of participants about the research process and build a relationship between the agency and participants.

\section{Data Collection and Analysis}

Participants were interviewed individually in their homes by either upper-level undergraduate or graduate students, who had been trained to converse with these specific refugee populations and the translators. All interviewers received training on the interview protocol, background information about the cultures of the participants, and text transcription. Furthermore, all interviewers had a strong research, academic, and community practice background. The students had taken courses in working with culturally, ethnically, and racially diverse populations. The interviews were conducted in the Chin dialect or Burmese (for the Burmese) or Kirundi (for the Burundians). Interviews were digitally audio recorded (time ranged from one to two hours) and then transcribed. At the beginning of each interview, the purpose of the research and the focus of the interview were explained. Since literacy was an issue for some of the participants, verbal consent was required. The interviews were semi-structured in that they focused on a series of open-ended questions related to participants' adaptation and resettlement experience. Participants also responded to questions that were related to their lives prior to coming to the United States, the services they received from the resettlement agencies, outcome experiences, family interactions, cultural support (e.g., sources and types of support, recommendations related to service delivery and demographic information). There was no tension between the interviewer, translators, and interviewees. This was also true even in cross-gendered interviews. Data collection spanned over seven months and also included focus group sessions as a part of the larger study.

After the interviews were transcribed, they were entered into NVivo qualitative coding software (Bazeley, 2008). Three members of the research team were responsible for the data analysis. Using qualitative content analysis, coders read the interviews to get a general sense of the content. Next, a coding scheme based on the interview framework (e.g. needs, barriers, and support) was developed. For this study, meaningful themes were any statements that two or more participants mentioned related to the established coding scheme. Coding for the first interview had low (33\%) inter-rater reliability. This led coders to revise the coding schema and the inter-rater reliability for the same first interview changed to $88 \%$. This process was repeated for the second and third interviews, with inter-rater agreement at $91 \%$ and $90 \%$ respectively. Each coder coded the rest of the interviews separately.

\section{FINDINGS}

The purpose of this study was to examine the impact of interpersonal relationships in refugee resettlement; specifically, the impact of agency and social support that 
individuals receive. The results of this study are presented in three parts. First, we discuss the impact of agency support; second, the types of resource support received and finally, network support on refugees' well-being. Furthermore, the unique experience of two ethnic groups, Burmese and Burundian, are also discussed. In order to protect participants' identity, the researchers have used pseudo-names in the findings section.

\section{Impact of Agency Support}

Not surprisingly, refugees' biggest and primary source of support came from resettlement agencies and staff members. As mentioned in the previous paragraphs, these agencies were the first to meet with refugees when they arrived and were responsible for providing adequate housing, employment, and healthcare services to families. In addition to providing and connecting refugees to resources, agency staff also provided emotional support and acceptance. Ernest, a 50-year-old Burundian male, echoed the voices of many refugees who looked to the agencies as part of their support system in their new environment:

This place where the refugee resettlement agency settled me, and then accepted me and then accepted to help me. So I doesn't want to move to somewhere else that I doesn't know anybody, I doesn't know if I gets help when I move... The first part was love. The refugee service people in refugee service they showed what love towards me and towards my family. They provided food. They provided me the house to stay in and then this house we are living in. I can't even mention all kind of good stuff they give, they provided then to us... Health Assistance, Okay. When I arrive here for the first few days they give us malaria medication. And then they took us to the hospital for screening and then for vaccine, different shots. Now we are over the six months they will have to be by their own, we don't speak English, we don't know even how to make appointment, how to follow up the appointment, we will have a big problem if they can be by themselves, we will not going to be able to take care of ourselves to go especially for to the hospital, follow up the doctor appointment. I still, I may still need help for that [doctor's appointment]. They provided the service but it's not yet time to tell us go by yourself because the English... We came here, we didn't know anybody, and we didn't know what, but now. The refugee [agency] was able to help us, to resettle us.

Ernest's excerpt illustrated refugees' dependence on their resettlement agencies. Whether it was finding housing, connecting them to health care services, or providing courses to learn English, these agencies were the first to contact refugees during their resettlement. More importantly, agency staff represented a new type of family. For instance, in the case of Ernest and his family, who have been displaced from family and friends for decades, staff members become part of their extended family. Agency staff showed them love and acceptance following their arrival in a foreign country. In some instances, refugees often cited their caseworkers as their friends who visited them when they were ill. Kwan, a Burmese male, recalled his caseworker coming to visit him at midnight when both he and his roommate had food poisoning. Thus, when the resettlement period is over and agencies deem refugees independent and not in need of 
extensive aid, refugees lose more than resources, they also lose a pivotal member of someone they now consider part of their family, and an important extension of support. Donathe, Ernest's wife, recalled that after the agency stopped supporting them, she could not leave her house. She said, "I don't know what to do, I don't know [anyone]". For individuals who have spent years (some decades) displaced, the loss of contact with agency staff adversely impact their wellbeing.

The loss of agency support as a source for access to services and a supportive network was a prevalent theme in most interviews. The typical resettlement period spans six months. The participants interviewed for this study were nearing or were beyond the six-month mark for receiving support from the agencies. This loss impacted Burmese and Burundians differently. For the Burmese participants, they were more likely in need of additional assistance with finding English classes or employment services. For instance, Aung expressed concerns about the agency's upcoming six month deadline. He said:

And the other difficult thing for me is that job, finding a job... there are several Burmese clients here now but only couple of people who have a job so the rest of them are here still [working with the agency] and then after 6 months our case will be ended then who will continue to help us. The agency may not be responsible for us when the case is over to find a job and things so job is so difficult.

The Burundian participants also struggled with learning a new language, and obtaining employment. However, their needs compounded with additional requirements such as food, appliances, and subsidized rent assistance, placing the Burundians in a more vulnerable position. Elizabeth and Martin, a Burundian couple, both mentioned that they have asked for extended help from the agency given that both were unemployed with six children living with them in the U.S. with a baby on the way, and a son to support in Tanzania. Elizabeth said:

I'd tell them just to extend time or just to teach people like me a lot of time, not like six months not like something like that. Or to help people like me who come here, like in this situation, to help me just to extend help that they give us. Like those, that money that they give us to buy food or I need to buy soaps, everything cause six months [is] not really enough for somebody like me.

The excerpt above illustrates the importance of resource support even after the sixmonth deadline. Due to a sluggish economy and low employment opportunities, only $64 \%$ of sampled participants (Burundians and Burmese) were employed. Most of them were employed either part-time or on a sporadic basis. Knowing that the agencies would soon withdraw support and services or knowing they had already withdrawn support led the Burmese to express disheartenment. One participant mentioned that due to his lack of employment opportunities, he may be perceived by others in his community as lazy despite his efforts to gain employment. Furthermore, the emphasis that the Asian culture places on the husband to be the provider for the family had led to some male participants to feel shame and discouraged because they could not provide the necessities for their families. 
The feelings of inadequacy were also expressed by the Burundian participants. Their families were larger than the Burmese, thus the loss of resource support was more detrimental. Furthermore, many of the Burundians financially support family members in Africa with the aid they receive from the agencies. Thus, the loss of agency support is also linked to their inability to provide assistance to other family members still living in refugee camps.

\section{Impact of Resource Support}

In addition to losing agency support, issues related to language acquisition, employment, obtaining community resources and housing were common service gaps noted in most of the interviews. Results indicated that some of these gaps were a result of lack of support that many refugees encountered during the resettlement period. The biggest concern for the Burmese and the Burundians was language acquisition as part of the agreement with the federal government stipulates that agencies are required to provide English courses to refugees. However, our data revealed that while all were enrolled in ESL courses, the majority had stopped attending classes before the courses were over. The lack of support that both ethnic groups experienced played a role in their discontinuation of the courses. Below are excerpts from two participants, one Burmese and one Burundian who expressed frustration related to the English courses in which they were enrolled. Aung, a Burmese participant said:

Um even though [the agency] has provided ESL classes that have been good, but I wish they way they provided us [the classes] ,,,,for instance okay nobody can speak Burmese language [in the classroom] then we're not allowed to speak Burmese language in the class than... all [of us are at ] different levels and then some of us don't know anything, even one word that what they're talking, what they're talking [in the classroom]... then when they [other people in the class] explain to us what the teacher was saying in Burmese then the teacher give us punishment again so then nothing is really beneficial so for [the] future.

Ornella, a Burundian participant said:

Yes, they show me the class where I can took[take]- - English classes but the problem was the communication. I was in the class, but when the teacher talk about something I don't know what is that [what is being taught]... From ESL classes, there is no help for me. Because even the teacher tried to teach me, I don't understand anything. So, but, for sewing circle, it's okay. Because I had an interpreter in the sewing circle. But in the ESL class no, there is no interpreter.

Many participants expressed concern about how the classes were taught and so they stopped attending the course even before their six month resettlement period ended. More importantly, the instructor's insistence that the class only be taught in English indicated that they felt little support attending the classes. In the case of Ornella, she stopped attending the English classes and instead found a sewing group in which she could communicate with other members of her ethnic group. The sewing groups, which were not created to teach English, however, were a source of social support for her. Emmanuel, 
a 47 year-old Burundian man, found the class and the instructor disrespectful because his unique needs were not being heard:

They [the staff at the resettlement agency] don't respect me. This [ESL instruction] doesn't match my culture. Because they know that and we told them that we really need somebody who speaks our language to tell, but they didn't look for somebody who, they didn't even want to look for somebody who can [speak our language]. Yeah and teach us. It's doesn't really, it's not, they didn't, it's not respect for us or they didn't listen to us, something like that.

The lack of support that our participants received during these ESL course led to feelings of frustration and disrespect. This, in turn, dissuaded them from attending the ESL classes. Speaking English is an integral part of acculturating in the U.S. It is linked to finding employment, increasing people's social support and a host of other resources. It was not surprising that many of the participants from both ethnic groups stated that their lack of experience with the English language prevented them from becoming independent U.S. residents.

Housing was another concern also linked to the support that refugees received during the resettlement period. Common issues related to housing included paying rent, living in dangerous neighborhoods, or not having any furniture in their homes. For instance, MinTun and her family mentioned that they stopped receiving resource support from the refugee agencies three months after their arrival. Due to the lack of assistance, they struggled to pay their rent and buy food. She said:

Oh, so no I didn't get anything starting from after three months... I would be very happy if somebody ask me, you know "how can I help, something" because right now I want to get assistance to cover for the living stuff, I mean, the basic thing is the food stamp for the whole family because right now only my husband has a job and after they are paying renting fees all [the money] is gone.

Victor and his wife, Kamariza, both mentioned that the house they stayed in had no furniture, microwave or other basic necessities such as soap, or adequate food. Victor said:

I think that we can follow the American culture, yeah um but um [in the] house you have chair [s], you have tables, but we don't really they didn't give us those chairs [or] tables. Everything you see [here] they are even broken. I took them (pointing at chairs) from the outside, people they throw them away and then I took them and put them in the house. We didn't get the support we supposed to get like we don't have microwave, we don't have toaster or something like that.

Kamariza echoed her husband's words and further mentioned that the lack of furniture in their home impacted their family's ability to associate with other Burundians.

The link between housing and social support highlights several challenges to refugees' wellbeing. First, the agencies have placed families in housing they cannot afford. In Min-Tun's case, she repeatedly asked for her agency's support in either paying the rent or helping to find affordable housing. She mentioned that she would welcome 
someone from the agency asking her if she needed help. The second challenge was the poor state of the apartments and lack of furniture in refugees' homes. This problem was not limited to individual functioning, but also linked to social support and isolation. Kamariza and her family do not socialize with other families due to their embarrassment over not having a place for guests to sit. This may not seem important from an American perspective. However, in some cultures around the globe, not being able to welcome guests into their home can be viewed as disrespectful and lead to individuals being ostracized within their own cultural groups. Furthermore, Victor, Kamariza's husband, links his lack of furnishings to being non-American. This is due to his assumption that real Americans have furniture and his lack of furniture meant he did not see himself as part of the dominant group and culture. From his perspective, although he and his family have finally made it to the United States - a free and safe country, they have not found a home, community or identity that fits them.

\section{Social Support and Supportive Networks}

While needs across the two groups were parallel, as noted in the previous sections, we did notice a disparity in access to resources that was directly linked to refugee groups' social ties. Overall, we noticed that the Burmese participants were better able to meet most of their basic needs, while the Burundians were struggling to obtain basic resources such as adequate shelter, sufficient food, or proper medical care. This disparity may be rooted in the perceived preferential treatment that some refugees received over others. For instance, Ninnette, a Burundian woman, expressed her frustration with the agency that resettled her family:

They give me no money they were giving others so they didn't help me. I don't trust them cause they didn't help me like others. They didn't treat me like others.... I was dreaming of speaking out to [the agency] to, yeah, cause to say, we came under same condition as other refugees. I go in their house I found they have money you [the agency] give that money to them you always give them money every week but you didn't give that money to me. If I knew English I should come to court.

Ninnette, like many Burundians, does not understand why her family's rent is not subsidized, why she does not have workable appliances, or why she does not receive employment aid? Even the Burmese participants noticed the preferential treatment that they received over others. Min-Tun recalls meeting another refugee couple who were not receiving any assistance from their resettlement agency.

Like us they resettle some of our friends and um some relatives also in the city, but totally different from the way from us. So they [the other agencies] don't care, it seems to me that they don't care [about] their clients that much, they don't visit them. Because, my wife, a place where we attended ESL together with the other couple [re] settled by the other agency, they told us that one day in the class, ESL classes they didn't have anything to eat, even rice. Rice is staple food for Asians and they didn't even have rice to eat, nothing. They [the agency] just brought them to the apartment; they just left [them] there. No food, no telephone 
and nothing so they [the other couple] almost um they were starving... The[ir] black neighbors who are also immigrants probably [dealt with the same issue] and then they almost beg for food.

These two excerpts illustrated the amount of support that refugees received differed by families, ethnic groups and within agencies in the same area. In the case of Ninette, she expressed that she would like to take the agencies to court due to perceived unfair treatment. However, her limited grasp of English prevented her from seeking judicial action and equality in fair access to resources and supports.

Due to inequality in obtaining resources from the refugee agencies, participants were actively seeking help from their supportive networks. For the Burmese, supportive networks are typically family and church members. Min Tun mentioned that due to the large Burmese community in the area, she is able to attend school and plan for the future. For instance, she mentioned, "our plan, so far, is that my mother-in-law would take care of the kids when I go to school and once we can save money, we want to support [provide] some money to my mother-in-law”. Furthermore, she expressed that due to the services she received from her agency, she is able to host other families at her home. This is a role that she enjoys because she is able to provide assistance to newly arrived families.

Providing support, either emotional or tangible, was a common theme within the Burmese community. Often the Burmese utilized their support systems to provide childcare assistance, emotional support and requisite services. Lwin mentioned that his neighbor, who was sponsored by another resettlement agency, relied on him to provide support:

Because the lady whom I just said who is living across the street, across hall, and she was sick because she's pregnant you know like couple months; she's sick and she called the case manager at [the other agency] and then they told her that um if she were dying [to call] and if she's just like regular sick don't call us [the agency], but only if you're really, really emergency and really dying then call us.

So that's what that lady told me again, [this is] the way [other agency]

responded to her so that made me so upset.

Lwin and his family stepped in to aid the pregnant woman often taking her food and helping her get prenatal medical care. All of these services were supposed to be provided by the agencies. Instead, the Burmese community is coming together to help each other.

The Burmese, in addition to providing support to family and friends, also received support through religious institutions. Although the Burmese participants knew few people when they first arrived, their common religion and language allowed them to connect with other Burmese families. Through this networking opportunity they were able to receive clothing, food, furniture, and emotional support. For instance, both Aung and his wife, Suu-Kyi, mentioned multiple opportunities that Burmese have to engage in networking. Aung said, "we, our Burmese community, have worship services Saturdays, every Saturday night. We call [go to this church]... even among Chin different dialects 
and different opinions". These churches were places that Burmese families could connect with each other and share integral services and needs.

In contrast, the Burundians did not receive the same support from the community agencies as the Burmese. To counter this lack of assistance, the Burundians often relied on other people outside of their family unit to provide resources. Previous excerpts illustrated that Burundians got assistance from their neighbors to acquire material goods such as food and furniture. Others got items they needed from the streets often picking necessities like furniture from other people's garbage. One major source of support for many Burundians was the interpreters used in this study. In one interview, the interpreter mentioned that as the only Burundian living near participants, he sometimes brings the families food. He said, "I [the interpreter] give them food, I bought food for them when they were hungry and I give them clothes, shoes. I was advising them, I was telling them many things about life”. The interpreters were responsible for coordinating any social gathering between the Central African refugees. These gatherings were often a collage of different African people. However, due to barriers such as transportation, language, and communication, the events were often cancelled or had low attendance. For instance, the interpreter mentioned:

The reason why I say no [the reason why there were no cultural events is] I work with them [I coordinate the cultural events] most of the time... So, hmm, that event never happen, didn't happen... I don't know the date yet [for the next cultural event], but we're trying to do that but for now no.

The reliance that many Burundians have on the interpreters does present a challenge for the interpreter. In one interview, the interpreter expressed remorse that he had to cancel a scheduled appointment to help another Burundian the day his wife went into labor.

As illustrated above, help-seeking strategies differ by ethnic groups. Our Burmese participants had more sources for support than the Burundians. This difference in supportive network is due to the proximity in which the agencies resettle ethnic groups. The Burmese were more likely to be resettled close to each other; while the Burundians were spread apart. Given that many refugees do not have adequate transportation, often relying on buses for travel, the Burundians had a harder time forming connections with other families from their ethnic group. Furthermore, the Burmese community had access to religious institutions, which tailored services to their ethnic group. As stated in previous excerpts, services were held in multiple languages and dialects for the Burmese. This was not the case for the Burundians; in fact, none of our participants mentioned attending church services held in their native language. Several reasons could be attributed to the lack of community resources available to Burundian families. The language barrier that many refugees encountered may have hindered Burundians from learning about services available to them. While the Burmese also encounter these language challenges, the fact that they were resettled (in large numbers) near each other may have caused better organization in the community to tailor some of their services to the group. 


\section{LIMITATIONS}

There are several caveats to the findings of this study. First, the interviews were collected with interpreters recruited from the resettlement agencies. As stated earlier in this research, interpreters were hired because of their connections and knowledge of their respective communities. Although participants provided valuable information about their experiences with the agencies, they may have felt some pressure to frame their responses in a more positive light due to the relationship between the interpreters and the agencies. The researchers were aware of the precarious position that the participants were placed when hiring interpreters connected to the agencies. Thus, the importance of confidentiality was emphasized at various phases of the study to both the interpreters and the participants. In addition to issues of confidentiality, concerns over recruitment may also be a limitation. Recruitment of participants was done with the help of the resettlement agencies. Thus, these results only reflect the perspectives of refugees who rely or have relied on resettlement agencies. There is anecdotal evidence from our interviews that suggests that not all refugees utilize the agencies' services. However, due to our recruitment strategies, we were not able to capture such experiences in this study. Finally, this study failed to capture the long-term relational impact of social support on both populations. Future research should examine the long-term impact of these challenges on refugees and their families.

\section{DISCUSSION}

Despite the limitations found in this study, the interviews do illuminate several important findings. First is the importance of "the agency" as a source of emotional and resource support during the resettlement period. As illustrated in the excerpts, agency staff represents a new family for refugees. Back in their home countries, it would not be unheard of for families to depend on their kinship ties to help get valuable resources and emotional support during times of war and displacement. This practice is continued when refugees come to the U.S., and often the agency staff becomes family. As pivotal as the resources are to refugees, the emotional support that the agency provides is just as vital. The six-month deadline removes an integral part of their resettlement-the agency worker who is viewed as family member who is a central link to refugees creating a community may not be available anymore. During the first year of resettlement, many refugees do not know other families. The agency staff fills in this gap. Thus, when that support is gone, the loss is doubly impactful in that families have lost a networking resource and a key person who is their connection to vital emotional support.

The second important finding from our data is impact of agency support on individual functioning and extended family ties. Individuals from non western families typically depend on familiar ties to help them cope during times of need. So, when families move to the U.S., they often support other relatives in their countries of origin. In our sample, the Burundian families mentioned that they supported children, parents, siblings and in-laws back in Tanzania using funds given to them by the agencies. When the agency is no longer financially supporting or providing rental subsidizes to families, many relatives in the country of origin are also negatively impacted. While it is not the 
agency's responsibility to provide aid to extended families, it is important to understand the cultural context that influences this behavior. Both ethnic groups respect traditional values, which encourage them to put the community's needs first ahead of their own. To delineate from this tradition means that the individual rejects their cultural heritage and is turning their back on other people who have assisted them in times of crisis. If it becomes known within the American refugee community that an individual is withholding or not giving support to relatives who are struggling to survive back in their home countries, that individual could be ostracized and cut off from his or her ethnic community.

The third important finding from our interviews is the importance of community ties to refugees' well-being. The excerpts above indicate that when agency support ends, individuals depend on other family members, friends, and churches to fill in the support gap. Our Burmese participants were resettled close to each other; thus, they were able to provide resources and emotional support to other families. Furthermore, since they received adequate help, they were able to provide same to other newly resettled members of the community. This was not the case of the Burundian participants who were resettled away from each other. Due to distance, the Burundian participants were not able to form community ties with each other. Thus, they had more difficulties creating a home and a community with individuals of the same ethnic background. Furthermore, the link of support observed in the Burmese sample did not develop in the Burundian community.

Taken together, these findings also highlight the need and importance of social workers in the resettlement process. First, social workers in their interactions with refugees know the unique challenges that each ethnic group encounters during and after the resettlement period. Their firsthand knowledge could be used to inform policy related to successful resettlement for families. In our sample, social workers like the first author of this article could inform policy makers about the importance of developing a community in order to help families get resources and support from community organizations. Furthermore, social workers also have the capacity to locate and work with key individuals in these marginalized groups who can be trained to become leaders for their respective communities. Working with the leaders, social workers could help bridge the gaps in service delivery and foster new avenues in which refugees can get services from the community while staying connected to their ethnic groups.

To conclude, community and mutual support are necessary aspects for well-being. In cases where individuals have undergone tremendous trauma, strain and upheaval, these ties become doubly important as it is now connected to resources and acculturation. Refugees typically leave their home countries due to lack of resources and are in need of a safe community environment. Coming to the U.S., the loss of these community ties and social support make it difficult for them to acclimate to the new culture and community environment. When resettling refugees in the U.S., agencies must take into account the importance of these factors. As suggested in the excerpts, having proximal support such as having family members or others from the same ethnic group nearby helps refugees cope with the stress of resettlement. Thus, future resettlements must work toward building a community for these families. This can be accomplished by resettling members of similar ethnic groups in close proximity to each other, facilitating more networking within ethnic groups, and encouraging other community organizations to 
provide services that fit the cultural expectations of refugee groups while giving them an opportunity to sustain and create new anchors that will ultimately strengthen their community connections. In conclusion, social workers and other service providers need to better understand the diverse array of experiences that refugees face so they can better tailor service and supports that will fit the unique needs of different ethnic groups.

\section{References}

Adepoju, A. (2006). Views on migration in sub-saharan Africa: Proceedings of an African migration Alliance workshop. In C. Cross, D. Gelderblom, N. Roux, \& J. Mafukidze (Eds.), Leading issues in international migration in Sub-Saharan Africa (pp. 25-47). Cape Town: HSRC Press.

Bazeley, P. (2008). Qualitative data analysis with nvivo. Los Angeles: Sage.

Bosch, K., \& Bergen, M. B. (2006). The influence of supportive and nonsupportive persons in helping rural women in abusive partner relationships become free from abuse. Journal of Family Violence, 21(5), 311-320.

Cardozo, B. L., Talley, L., Burton, A., \& Crawford, C. (2004). Karenni refugees living in Thai-Burmese border camps: traumatic experiences, mental health outcomes, and social functioning. Social Science and Medicine, 58(12), 2637-2644.

Carlson, B. E., McNutt, L., Choi, D. Y., \& Rose, I. M. (2002). Intimate partner abuse and mental health: The role of social support and other protective factors. Violence against women, 8(6), 720-745.

Costa, R. (2006). The administration of justice in refugee camps: A study of practice. In Legal and protection policy research series. Retrieved from United Nations High Commissioner for Refugees, Department of International Protection website: http://www.unhcr.org/pages/49c3646cc8.html

Daley, P. (1991). Gender, displacement and social reproduction: Settling Burundi refugees in Western Tanzania. Journal of Refugee Studies, 4(3), 248-266

Deacon, Z., \& Sullivan, C. (2009). Responding to the complex and gendered needs of refugee women. Affilia: Journal of Women and Social Work, 24(3), 272-284.

Docquier, F., Lohest, O., \& Marfouk, A. (2007). Brain drain in developing countries. The World Bank Economic Review, 21(2), 193-218.

Draminsky-Petersen, H., Worm, L., Zander-Olsen, M., Ussing, B., \& Harding, O. J. (2000). Human rights violations in Burma/Myanmar. Danish Medical Bulletin, 47, 359-363.

Goodkind, J. R., Gillum, T. L., Bybee, D. I., \& Sullivan, C. M. (2003). The impact of family and friends' reactions on the well-being of women with abusive partners. Violence Against Women, 9(3), 347-373.

Haver, K., Hatungimana, F., \& Tennant, V. (2009). Money matters: An evaluation of the use of cash grants in UNHCR 's voluntary repatriation and in Burundi. Geneva, 
Switzerland: United Nations High Commissioner for Refugees, Policy Development and Evaluation Services.

Hoofnagle, K., \& Rothe, D. L. (2010). Overlooked and overshadowed: The case of Burundi. Critical Criminology, 18(3), 169-189.

International Crisis Group. (1999). Burundian Refugees in Tanzania: The key factor to the Burundi Peace Process. (ICG Central Africa Report No. 12).Nairobi. Retrieved from http://www.crisisgroup.org/en/regions/africa/central-africa/burundi/012burundian-refugees-in-tanzania-the-key-factor-to-the-burundi-peace-process.aspx

Lang, H. J. (2002). Fear and sanctuary: Burmese refugees in Thailand. Ithaca: Cornell Southeast Asia Program.

Lewig, K., Arney, A., \& Salveron, M. (2010). Challenges to parenting in a new culture: Implications for child and family welfare. Evaluation and Program Planning, 33(3), 324-332.

Nawyn, S., Gjokaj, L., Agbényiga, D., \& Grace, B. (2012, in press). Linguistic isolation, social capital, and immigrant belonging. Journal of Contemporary Ethnography, 41.

Oetzel, J., Duran, B., Jiang, Y., \& Lucero, J. (2007). Social support and social undermining as correlates for alcohol, drug, and mental disorders in American Indian women presenting for primary care at an Indian health service hospital. Journal of Health Communication, 12(2), 187-206.

Schweitzer, R., Melville, F., Steel, Z., \& Lacherez, P. (2006). Trauma, post-migration living difficulities, and social support as predictors of psychological adjustment in resettled Sudanese refugees. Australian and New Zealand Journal of Psychiatry, 40(2), 179-187.

Simich, L., Beiser, M., \& Mawani, F. (2003). Social Support and the significane of shared experience in refugee migtation and resettlement. Western Journal of Nursing Research, 25(7), 872-891.

Simich, L., Beiser, M., Stewart, M., \& Mwakarimba, E. (2005). Providing social support for immigrants and refugees in Canada: Challenges and directions. Journal of Immigrant and Minority Health, 7(4), 259-268.

Singer, A., \& Wilson, J.H. (2008). From there to here: Refugee resettlement in Metropolitan America. Retrieved from The Brookings Institution: http://www.brookings.edu/ /media/Files/rc/reports/2006/09demographics_singer/200 60925_singer.pdf

United Nations High Commissioner for Refugees. (1951). Text of the 1951 Convention relating to the status of refugees. Retrieved from: http://www.unhcr.ch/cgibin/texis/vtx/protect?id=3c0762ea4

United Nations High Commissioner for Refugees. (2010). 2009 Global trends: Refugees, asylum-seekers, returnees, internally displaced and stateless persons. Retrieved from: http://www.unhcr.org/statistics 
United States Department of State. (2010). Fact Sheets 2011. Received from: http://www.state.gov/g/prm/rls/fs2011/index.htm

Verwimp, P., \& Van Bavel, J. (2005). Child survival and fertility of refugees in Rwanda. European Journal of Population, 21(2-3), 271-290.

Weinstein, H. M., Sarnoff, R. H., Gladstone, E., \& Lipson, J. G. (2000). Physical and psychological health issues of resettled refugees in the United States. Journal of Refugee Studies, 13(3), 303-327.

Whitaker, B. E. (2002). Refugees in Western Tanzania: The distribution of burdens and benefits among local hosts. Journal of Refugee Studies, 15(4), 339-350.

Willis, M., \& Nkwocha, O. (2006). Health and related factors for Sudanese refugees in Nebraska. Journal of Immigrant and Minority Health, 8(1), 19-35.

Wright, C.A. (2008). Kachin refugee women's work identity: Narrative in transition. Unpublished master's thesis. University of Texas at Arlington, Arlington, TX. (ProQuest Dissertations \& Theses database). Retrieved August 252011 from Pro Quest database.

\section{Author note:}

Address correspondence to: DeBrenna LaFa Agbényiga, PhD, LMSW, Assistant Professor, Michigan State University School of Social Work, 104 Baker Hall, East Lansing, MI 48823-1118. Email: agbenyi1@msu.edu 